\title{
JUSTIÇA DIGITAL E O FUTURO DA COMPETÊNCIA TERRITORIAL ${ }^{1}$
}

\section{DIGITAL JUSTICE AND THE FUTURE OF TERRITORIAL JURISDICTION}

\section{Arthur Künzel Salomão}

Mestre em Direito pela Fundação Escola Superior do Ministério Público (FMP) e Pós-graduando em Direito dos Negócios pela Universidade Federal do Rio Grande do Sul (UFRGS). Porto Alegre/RS.

\section{Marco Antônio Rodrigues}

Professor Adjunto de Direito Processual Civil da UERJ. Procurador do Estado do Rio de Janeiro. Sócio de LDCM Advogados. Pós-Doutor pela Universidade de Coimbra/Portugal. Doutor em Direito Processual e Mestre em Direito Público pela Universidade do Estado do Rio de Janeiro (UERJ). Master of Laws pela King's College London. Professor de cursos de pós-graduação pelo Brasil. Membro da International Association of Procedural Law, do Instituto Ibero-Americano de Direito Processual e do Instituto Brasileiro de Direito Processual. Rio de Janeiro/RJ. E-mail: marcoadsrodrigues@gmail.com

RESUMO: O presente artigo tem como objetivo principal relacionar a implementação do juízo digital com a competência territorial. Considerando os efeitos que a tecnologia ocasionou nos hábitos hodiernos, bem como a compreensão que o estudo do direito se compreende dentro de uma ciência social, é fato que o avanço tecnológico proporcionou alterações no meio jurídico. Assim, é inegável que atualmente o uso de aplicações de tecnologia apresentam uma perspectiva muito promissora para a prática jurídica, sendo capaz de oferecer aos operadores do direito possibilidades anteriormente inimagináveis.

\footnotetext{
${ }^{1}$ Artigo recebido em 30/04/2021 e aprovado em 02/06/2021.
} 
Com efeito, a estruturação de um juízo digital muito contribuiria para prestação jurisdicional, contribuindo com o funcionamento do poder judiciário, seja do ponto de vista qualitativo, como quantitativo.

PALAVRAS-CHAVE: Acesso à Justiça. Competência. Juízo 100\% Digital. Processo Civil. Tecnologia.

ABSTRACT: The main objective of this article is to relate the implementation of digital judgment to the territorial competence. Considering the effects that technology has had on today's habits, as well as the understanding that the study of law is understood within a social science, it is a fact that technological advances have provided changes in the legal environment. Thus, it is undeniable that currently the use of technology applications presents a very promising perspective for legal practice, being able to offer possibilities previously unimaginable. In this regard, the creation of limited territorial jurisdiction in favor of specialized digital courts would add a new option to access to justice. Furthermore, the structuring of a digital court would greatly contribute to jurisdictional provision, contributing to the functioning of the judiciary, from a qualitative and quantitative point of view.

KEYWORDS: Access to justice. Competence. Judge 100\% Digital. Civil Procedure. Technology

\section{Introdução}

A tecnologia vem gerando os mais diversos impactos na resolução de conflitos, o que foi sensivelmente acelerado em tempos de pandemia ${ }^{2}$. Como importantes mudanças nos últimos anos, pode-se elencar a utilização de mecanismos online de resolução de conflitos, como é o caso da plataforma consumidor.gov.br, cuja sistemática vem sendo trazida para os tribunais $^{3}$; assim como os julgamentos virtuais e os julgamentos e audiências por

2 Conforme o autor Marco Rodrigues já defendeu em: <https://www.jota.info/opiniao-eanalise/artigos/processos-judiciais-e-coronavirus-28032020 >. Acesso em 16 de julho de 2020.

${ }^{3}$ A plataforma foi integrada ao sistema PJE do Tribunal Regional da $1^{a}$ Região (TRF-1) e do Tribunal de Justiça do Distrito Federal e Territórios (TJDFT), após acordo entre o Tribunal e o Ministério da Justiça, tal como 
videoconferência, estes últimos muito desenvolvidos nos últimos meses, diante da pandemia. $^{4}$

Um dos muitos impactos que a tecnologia ainda pode gerar na resolução dos conflitos se refere à competência territorial: em qual medida as competências de foro podem ser revistas com a virtualização dos tribunais?

Isso pois, trata-se de uma temática que guarda ligação direta não somente com as disposições do Código de Processo Civil referentes ao instituto da competência, mas principalmente com o direito fundamental de acesso à justiça e com as demais garantias fundamentais processuais. Considerando que, a depender do mérito da causa a ser apreciado pelo juiz, a utilização do juízo digital pode representar uma forma de tramitação que favorece as partes, seja pelo conteúdo decisório da sentença ou até mesmo pela possibilidade de um julgador especializado na matéria objeto do processo.

Nesse sentido, o objeto do presente artigo é analisar o instituto da competência territorial à luz das possibilidades proporcionadas pelo processo digital. Contudo, não há pretensões de fazer com que um dos institutos se sobressaia ao outro, mas tão somente ponderar em que medida ambos podem contribuir para um melhor funcionamento da prestação jurisdicional.

Assim, no primeiro ponto será analisado o instituto da competência territorial, tanto sob uma perspectiva normativa como doutrinária. Discorreremos sobre as regras de competência vigentes no ordenamento jurídico atual, bem como seus requisitos para distribuir a atividade jurisdicional dentro do território nacional.

Posteriormente, será objeto de análise o direito fundamental de acesso à justiça, partindo-se da reflexão sobre a sua natureza de garantia fundamental e analisando suas implicações. Após, serão abordados os requisitos do juízo $100 \%$ digital, bem como abordadas hipóteses em que a ampliação da tramitação virtual de demandas pode significar uma importante ferramenta para a prestação jurisdicional, tanto pela perspectiva das partes como dos operadores do direito.

noticiado em: <https://agenciabrasil.ebc.com.br/justica/noticia/2019-10/consumidor-que-justica-seradirecionado-consumidorgovbr $>$. Acesso em 16 de julho de 2020.

${ }^{4}$ Como igualmente já abordamos em: <https://www.jota.info/opiniao-e-analise/artigos/processos-judiciais-ecoronavirus-28032020>. Acesso em 16 de julho de 2020. 
Por derradeiro, serão feitas considerações de como o desenvolvimento do processo digital pode significar uma transição de pensamento na doutrina processual, consubstanciando em eventuais supressões à competência territorial em face da competência adequada.

\section{Aspectos territoriais e o exercício da jurisdição}

A prestação jurisdicional sempre guardou relação direta com questões territoriais, principalmente quando se analisam as regras de competência para apreciação de determinada causa. Assim, utilizando-se de regras de competência pré-existentes ao surgimento do processo para afirmar como competente determinado juízo, seja em razão das partes, mérito da causa ou seu objeto, tanto no âmbito da jurisdição nacional, como internacional.

Quanto às regras de direito internacional privado, percebe-se que o exercício da jurisdição, como as próprias noções de Estado e soberania, está profundamente relacionado ao território. Quanto à atividade cognitiva, a existência de alguma conexão com o território costuma ser utilizada como critério para avaliar o interesse da jurisdição em apreciá-lo. Já quanto à tarefa executiva, o território é o próprio limite para o exercício da força, visto que um Estado não pode exercer sua força no território de outro, sob pena de violação à soberania. $^{5}$

Doravante, no que se refere à competência interna, sempre é necessário levar em consideração que a extensão do território brasileiro é de proporções continentais, o que significa dizer que a área abrangida território nacional é superior ao menor continente existente no globo terrestre, que corresponde a área ocupada pela Oceania, de $7.692 .024 \mathrm{~km}^{2}$. Atualmente, o país conta com um território de $8.514 .876 \mathrm{~km}^{2}$ de extensão, o que lhe garante a quinta posição quando se analisam os países de maior território no mundo, ficando atrás somente de Rússia, Canadá, China e Estados Unidos da América.

A grande dimensão do mapa brasileiro é demonstrada quando analisadas as extremidades de seu território, de modo que a distância compreendida de norte a sul é de 4.395 quilômetros, enquanto de leste a oeste é equivalente a 4.320 quilômetros. Nesses

\footnotetext{
${ }^{5}$ YARSHELL, Flávio Luiz; GOMES, Adriano Camargo. Internet e limites da jurisdição: Uma breve análise à luz do direito processual civil. In: WOLKART, Erik Navarro (coord.) et al. Direito, Processo e Tecnologia. 1. ed. São Paulo: Thomson Reuters Brasil, 2020, p. 26.
} 
termos, o Brasil representa um percentual de $47 \%$ de toda a terra emersa da América do Sul, bem como conta com aproximadamente metade da população residente no continente sulamericano.

Tais proporções continentais resultam em uma vasta riqueza cultural, compreendida entre as culturas regionais dos Estados membros, bem como na ampla diversidade de clima, terrenos, vegetação, entre outros. Considerando, contudo, a grande área ocupada pelo país, o legislador estabeleceu regras de competência territorial, com a pretensão de estabelecer regras para determinar qual juízo será competente para julgar o mérito de eventual processo judicial instaurado, levando em consideração as pessoas envolvidas e o tipo de controvérsia que deu causa a instauração da demanda judicial.

A competência é o poder de exercer a jurisdição nos limites estabelecidos por lei. É o âmbito dentro do qual o juiz pode exercer a jurisdição. ${ }^{6}$ Os requisitos para atribuição da competência dividem-na absoluta e relativa. Quando a escolha do juízo competente traduz uma forma de predominante tutela ao interesse público, fala-se em competência absoluta; já quando os critérios utilizados forem razões de presumido interesse das partes, será tratada como competência relativa.

Há diversos critérios para a definição da competência, e um deles se refere ao foro para processamento das ações. Especificamente no que versa sobre a competência territorial, deve ser considerado o elemento objetivo ou subjetivo, para determinar a comarca em que será apreciado o mérito do processo judicial em questão. Eventual falta desse elemento lança mão de outro dado subsidiário para determinar o foro da lide. Também em certos casos a lei estabelece um elemento especial, com o mesmo objetivo, e, na falta dele, institui ainda outro elemento subsidiário, tudo com o escopo de estabelecer a comarca em que tramitará a causa. Esse quadro permite classificar a competência de foro, em primeiro lugar, em (a) foro comum; e (b) foro especial. Ademais, nessas classes, há o (a) foro principal e o (b) foro subsidiário. É geral ou comum o foro para a causa, inexistindo foro especial. ${ }^{7}$

As competências territoriais são dispostas nos artigos 46 e seguintes do Código de Processo Civil ligadas a diferentes interesses, mormente à facilitação do acesso à justiça do

\footnotetext{
${ }^{6}$ DIDIER JUNIOR, Fredie. Curso de Direito Processual Civil. Vol. I. 19. ed. Salvador: JusPODVM, 2017, p. 222.

7 ASSIS, Araken de. Processo civil brasileiro, volume I [livro eletrônico]: parte geral: fundamentos e distribuição de conflitos / Araken de Asssis. -2 ed. -São Paulo. Editora Revista dos Tribunais, 2016. Capítulo 25 .
} 
autor ou do réu, ou a algum interesse da justiça. A título de exemplo, pelo artigo 46 do CPC, A ação fundada em direito pessoal ou em direito real sobre bens móveis será proposta, em regra, no foro de domicílio do réu. ${ }^{8}$

Dispõe o art. 46, caput, que tais ações serão propostas "em regra, no foro de domicílio do réu". Também é o foro principal. Especial, ao invés, é o foro que derroga o comum. Por esse motivo, o foro geral sempre é definido por exclusão de algum foro especial. Por exemplo, constitui foro especial, relativamente à regra do art. 46, caput, o art. 53, V, que autoriza a vítima de acidente de trânsito a demandar o réu no foro do seu domicílio, em lugar do domicílio do réu. Todavia, não se identificando o domicílio do réu, o art. 46, § 2. , estabelece que o autor o demandará no lugar em que for encontrado ou no seu próprio domicílio. Esses foros têm caráter subsidiário e, como o autor pode optar entre eles, caracterizam-se como foros concorrentes. Se, entretanto, autor e réu não dispõem de domicílio ou de residência no Brasil, ou seja, na falta de qualquer dado, então o art. 46, $\S$ 3. ${ }^{\circ}$, segunda parte, adotou norma de encerramento, prevendo que a demanda pode tramitar em qualquer foro.

Outro exemplo pode ser extraído do mesmo artigo 53, que traz diversos foros de competência territorial concorrente, os quais excepcionam a regra do artigo 46. A título de exemplo, o artigo 53, inciso I, elenca diversos foros para a ação de divórcio, separação, anulação de casamento e reconhecimento ou dissolução de união estável e, em sua alínea "a", prevê o domicílio do guardião do filho incapaz. O CPC parte do pressuposto de que o cônjuge guardião de filho incapaz possui menor mobilidade e disponibilidade, de forma que deve ser privilegiado quanto à competência para as ações de dissolução da sociedade conjugal ou união estável. ${ }^{9}$

Entretanto, com a popularização dos meios digitais, as características dessa rede reduzem significativamente a relevância de aspectos territoriais nas relações humanas: as conexões são estabelecidas sem fronteiras. ${ }^{10} \mathrm{~A}$ falta de aderência territorial faz com que

\footnotetext{
8 Trata-se, como aponta Humberto Theodoro Junior, do "foro comum [...] Vale dizer, que, em princípio, qualquer réu tem o direito de ser demandado na comarca ou na seção judiciária em que é domiciliado, se não há, em razão da matéria, competência especial diversa." (THEODORO JUNIOR, Humberto. Curso de Direito Processual Civil. Vol. I. 59 ed. Rio de Janeiro: Forense, 2018, p. 251).

${ }^{9}$ NERY JÚNIOR, Nelson; NERY, Rosa Maria de Andrade. Código de Processo Civil Comentado. 18 ed. São Paulo: Revista dos Tribunais, 2018, p. 214.

${ }^{10}$ LEINER BARRY M. et al A Brief History of Internet. ACM SIGCOMM Computer Communication Review, v. 39, n 5, Oct. 2009.
} 
essas interações frequentemente extrapolem fronteiras, produzindo efeitos em uma multiplicidade de países. ${ }^{11}$ Considerando que a territorialidade é um elemento constitutivo das concepções de jurisdição e, também, de soberania, esses impactos geram questionamentos a respeito de suas limitações em relação à internet.

Com a proliferação dos processos eletrônicos, pode-se pensar em novas formas de conciliar o juiz natural com a especialização não só de unidades ou órgãos jurisdicionais (justiças internas ou câmaras especializadas), mas também e sobretudo com a especialização de juízes. Magistrados especializados em certas matérias poderiam ser incluídos em listas e terem os processos distribuídos em função da sua especialização, podendo julgá-los de qualquer localização geográfica. ${ }^{12}$

Visto que, a rigor, o próprio Código de Processo Civil contempla a utilidade da tecnologia, quando dispõe, em seu artigo $236, \S 3^{\circ}$, admitindo a prática de atos processuais por meio de videoconferência ou outro recurso tecnológico que proporcione a comunicação síncrona. Portanto, acaba-se por prescindir de um encontro presencial das partes, otimizando tempo e custos decorrentes tanto da intimação das partes para realização da audiência quanto da própria realização do ato processual, que não precisará ocupar um lugar físico, nem mesmo exigir o deslocamento das partes, sendo tais pontos alguns dos responsáveis por atribuírem ao processo judicial maior morosidade. ${ }^{13}$

Com efeito, a pretensão de atribuir maior efetividade e celeridade à prestação jurisdicional deve ser uma das principais medidas para melhorar o funcionamento da justiça brasileira. Visto que, conforme Relatório do Conselho Nacional de Justiça, ${ }^{14}$ no ano de 2016 apresentava uma taxa de congestionamento bruta de 72,2\%, ou seja, dos 74 milhões de processos tramitando, menos de 30\% foram instaurados naquele mesmo ano. Assim, no período de exercício subsequente, a apuração do número de processos nas repartições públicas correspondia a 80,1 milhões. ${ }^{15}$ No que versa sobre o congestionamento judicial,

\footnotetext{
${ }^{11}$ KOHL, Uta. Jurisdiction and the internet: Regulatory competence over Online Activity. New York: Cambridge University Press, 2010, p. 104.

${ }^{12}$ CABRAL, Antonio do Passo. Processo e Tecnologia: novas tendências. In: WOLKART, Erik Navarro (coord.) et al. Direito, Processo e Tecnologia. 1. ed. São Paulo: Thomson Reuters Brasil, 2020, p.107.

${ }^{13}$ VASCONCELOS, Ronaldo; CARNAUUBA, César Augusto Martins. Custo de Transação do Processo e Online Dispute Resolution: um sistema multiportas 4.0 economicamente eficiente. In: WOLKART, Erik Navarro (coord.) et al. Direito, Processo e Tecnologia. 1. ed. São Paulo: Thomson Reuters Brasil, 2020, p. 625-626.

${ }^{14}$ BRASIL, Conselho Nacional de Justiça. Relatório Justiça em números 2016. Brasília: CNJ, 2016, p. 43

${ }^{15}$ BRASIL, Conselho Nacional de Justiça. Relatório Justiça em números 2018. Brasília: CNJ, 2018 p. 73.
} 
percebe-se que o estoque de processos só aumenta, totalizando desde o ano de 2009 um aumento de $19,4 \%$, equivalendo a 9,6 milhões de demandas. ${ }^{16}$

\section{Acesso à justiça: Um lugar ou um serviço?}

$\mathrm{O}$ artigo $5^{\circ}, \mathrm{XXXV}$, da Constituição da República veicula o princípio da inafastabilidade da jurisdição, que veda que sejam excluídos da apreciação do Poder Judiciário lesão ou ameaça de lesão a direito. Dessa forma, resta claro que qualquer norma infraconstitucional que procure restringir a possibilidade de apreciação de violação ou de mero risco a direito não pode ser admitida, por ofensa ao sistema fundamental de garantias constitucionais.

Desse dispositivo constitucional, assim como do artigo $3^{\circ}$ do Código de Processo Civil, também pode ser extraído o direito de acesso a uma prestação jurisdicional justa e efetiva, enquanto garantia essencial da dignidade da pessoa humana. ${ }^{17}$

Com a pretensão de realizar uma análise sobre a evolução histórica da doutrina processualista no que versa sobre a conceituação do acesso à justiça, Mauro Cappelletti e Bryant Garth conceituam-no como um sistema jurídico capaz de proporcionar às pessoas a possibilidade de reivindicar seus direitos e resolver seus litígios sob os auspícios do Estado, devendo ser igualmente acessível a todos e capaz de produzir resultados que sejam individual e socialmente justos. ${ }^{18}$

Por sua vez, Richard Susskind ressalta a pretensão de que um dia o site dos poderes judiciários seja tão acessível aos cidadãos, como são os sites de comércio eletrônico e redes sociais. $\mathrm{O}$ autor conceitua o acesso à justiça não somente como uma forma de resolver disputas, mas também de conter e evitar demandas judiciais.

Em ambos os conceitos, percebe-se que a tecnologia tem um papel importante para concretizar da melhor forma o direito fundamental em questão, o qual ocupa posição equivalente a um dos pilares do Estado Democrático de Direito. ${ }^{19}$ Sobre isso, são exemplos

\footnotetext{
${ }^{16}$ BRASIL, Conselho Nacional de Justiça. Relatório Justiça em números 2016. Brasília: CNJ, 2016, p. 222

${ }^{17}$ RODRIGUES, Marco Antonio dos Santos. A modificação do pedido e a causa de pedir no processo civil. Rio de Janeiro: GZ, 2014, p. 128.

${ }^{18}$ CAPPELLETTI, Mauro e GARTH, Bryant. Acesso à justiça. Porto Alegre: Sergio Antonio Fabris Editor, 1988. p. 8.

19 Especificamente sobre o tema, ver RODRIGUES, Marco Antonio. Acesso à justiça, resolução on-line de conflitos e interesse de agir. In: Revista de Processo, vol. 314, p. 39-53, abril/2021.
} 
de aplicação de tecnologias disruptivas disponíveis para a prática jurídica, a automação documental, conexão constante via internet, mercados legais eletrônicos (medidores on-line de reputação, comparativos de preços e leilões de serviços), ensino on-line, consultoria legal online, plataformas jurídicas abertas, comunidades on-line colaborativas fechadas, automatização de trabalhos repetitivos e de projetos, resolução on-line de conflitos (Online Dispute Resolution - ODR), análise automatizada de documentos, previsão de resultados de processos e respostas automáticas a dúvidas legais em linguagem natural e embedded legal knowledge, termo de difícil tradução, mas que significa a capacidade de os produtos vendidos no mercado observarem os comportamentos desconformes com a lei, por exemplo, um carro que identifica se o motorista está alcoolizado. ${ }^{20}$

Quanto à acessibilidade a prestação jurisdicional, a pretensão de Richard Susskind é de que em um futuro próximo existam sistemas de justiça capazes de promover a acessibilidade e de operabilidade tão intuitiva quanto a utilização de qualquer outro site de compras on-line ou rede social. ${ }^{21}$

Todavia, na mesma medida que sua aplicação pode proporcionar uma otimização de tempo voltada para o processo da atividade exercida, há também que se considerar as tecnologias que apresentam natureza disruptiva, acabando por romper com os padrões anteriores à sua invenção. Outrossim, percebe-se que assim como a tecnologia pode solucionar problemas, aprimorar procedimentos e otimizar tempo, também pode gerar efeitos colaterais que acabam por criar novos empecilhos, ou até mesmo acentuar barreiras já existentes.

Assim, a análise de tal problemática social poder tornar o acesso ao ambiente virtual mais um fator de exclusão, entre vários outros já existentes, para a população que vive nas periferias urbanas no Brasil. ${ }^{22}$ Em resposta à eventual exclusão decorrente das cortes online, o autor afirma que, ainda que a resolução on-line de conflitos possa acarretar exclusão para as pessoas que vivem em situação de vulnerabilidade social, há de se mencionar que o

\footnotetext{
${ }^{20}$ SUSSKIND, Richard. Tomorrow Lawyers: An Introduction to your Future. 2. ed. London: Oxford University, 2017, p. 50-51

${ }^{21}$ SUSSKIND, Richard. Online courts and the future of justice. Oxford University Press. UK, 2019, p. 97.

${ }^{22}$ Conforme o "Acesso à Internet e à televisão e posse de telefone móvel celular para uso pessoal 2017", publicado pelo IBGE, apenas $69,8 \%$ das pessoas tiveram acesso à internet no Brasil no ano em que foi realizada a pesquisa.
} 
mesmo já ocorre em escalas possivelmente superiores nas salas de audiência e tribunais físicos. ${ }^{23}$

Nesse contexto, percebe-se que é característico da doutrina processual moderna o aclaramento e agilização dos meios de acesso à ordem jurídica justa, mediante um sistema jurídico que tenha como questão central a capacidade de produção de resultados aptos a pacificar as pessoas e eliminar os conflitos de forma justa. ${ }^{24}$ Assim, partindo-se dessa premissa, questiona-se até que ponto se torna benéfica para toda e qualquer demanda judicial a utilização das regras de competência territorial.

Considerando que a concepção de acesso à justiça vai muito além do estabelecimento de um lugar para resolução dos conflitos, de modo que as alterações sociais trazem, em grande medida, uma desconexão com o espaço territorial demonstrado na conexão que transcende as fronteiras tanto internas do país, como até mesmo sob o ponto de vista internacional. Logo, a perspectiva de análise deve-se considerar a aptidão do sistema de justiça em oferecer a melhor prestação jurisdicional dentro do contexto social em que vigora.

Nessa perspectiva, questiona-se eventual possibilidade da ampliação do acesso à justiça através da implementação de uma justiça virtual apresenta uma perspectiva benéfica ao funcionamento da justiça brasileira. Sobretudo quanto abordado de maneira que se desconecte cada vez mais do aspecto territorial, ao par que se aproxime com uma melhor prestação jurisdicional, bem como funcionamento do poder judiciário em sentido geral.

Isso pois, não é raro no cenário atual da prestação jurisdicional nacional a existência de comarcas que não apresente grande diversidade de varas judiciais especializadas. No mesmo sentido, a grande maioria delas ainda apresenta sinais do congestionamento judicial, que poderia ser combatido por meio da implementação de varas digitais especializadas que desonerem a carga de trabalho físico dessas comarcas.

Com efeito, o processo virtual significaria uma nova porta de entrada no Poder Judiciário, a qual seria capaz de contribuir com a prestação jurisdicional, seja do ponto de vista qualitativo, como quantitativo, na medida em que as demandas que apresentem características passíveis de julgamento virtual fossem destinadas para justiça digital por meio da manifestação dos jurisdicionados em submeter o julgamento ao juízo digital.

\footnotetext{
${ }^{23}$ SUSSKIND, Richard. Online courts and the future of justice. Oxford University Press. UK, 2019, p. 221. ${ }^{24}$ DINAMARCO. Cândido Rangel. A instrumentalidade do processo. 12. ed. São Paulo: Malheiros, 2005. p. 392.
} 
De qualquer forma, a ampliação do juízo virtual no Brasil provavelmente não irá representar na solução de todos os problemas quanto ao exercício da jurisdição, pois as barreiras para o acesso à justiça efetivo são diversas e inter-relacionadas, sendo necessário, outrossim, buscar enfrentar outras causas de judicialização excessiva. Contudo, apresenta uma perspectiva promissora, diante das possibilidades proporcionadas pela tecnologia, a qual é capaz de fornecer ferramentas inovadores e capazes de mitigar problemas enfrentados pela prática jurídica.

\section{O Juízo $100 \%$ Digital (Resolução no $345 / 2020$ do CNJ)}

Em relação à implementação das novas tecnologias devem-se destacar alguns pontos para assegurar o sucesso da aplicação, como: entender como a tecnologia impactará a interação entre as pessoas/partes, analisar as diferentes formas como os conflitos podem ter sido originados, avaliar como a tecnologia poderá contribuir de forma eficiente para sua solução. É preciso também ponderar os riscos e benefícios que a tecnologia poderá trazer para a resolução do conflito, assim como analisar o impacto nos profissionais dos métodos alternativos para operacionalizar soluções tecnológicas. ${ }^{25}$

No decorrer dos últimos vinte anos, a evolução da ciência e o desenvolvimento de sistemas tecnológicos, os quais produziram efeitos que culminaram em mudanças em basicamente todas as áreas do conhecimento humano, demonstraram que em algumas dessas áreas há maior resistência para inserção de mudanças do que em outras. Tal constatação não é nada surpreendente, e se justifica exatamente pela maior valorização da história e tradição da área em questão, como ocorre justamente no direito, marcado pelo respeito à liturgia, prestígio às tradições e uma atribuição de sentido que beira o poético no que versa sobre o exercício da profissão. A resistência quanto à assimilação de novas tecnologias por parte dos operadores do direito em razão de desmedido e desnecessário conservadorismo é demonstrada em situações como no ano de 1929, quando o Tribunal da Relação de Minas Gerais anulou uma sentença criminal porque ela tinha sido datilografada, fundamentando a decisão pelo fato de que a utilização da máquina de escrever resulta em uma antecipação da

\footnotetext{
${ }^{25}$ ECKSCHMIDT, Thomas; MUHR, Diana; MAGALHÃES, Mario E. S. Do Conflito ao Acordo na Era Digital (Meios Eletrônicos para Solução de Conflitos). 2. ed. São Paulo: Moderattus, 2016, posição de 1110/3560 (Kindle).
} 
publicidade do ato judicial. De forma semelhante, na década de 1990, restaram anuladas sentenças judiciais elaboradas com utilização do microcomputador, por receio de que a reprodutibilidade do texto impedia o estudo acurado do processo a que devem se dedicar os juízes. ${ }^{26}$

Ressalta-se, contudo, que os movimentos do Conselho Nacional de Justiça para implementação de aplicações tecnológicas na melhoria da prestação jurisdicional no país se mostram promissores, já havendo sido objeto de resolução aplicações de inteligência artificial, juízo digital, entre outros. Tal abordagem conjunta do direito e tecnologia já apresenta resultados, ao exemplo da adoção do processo eletrônico no Brasil, que anos atrás era uma realidade difícil de ser imaginada, de modo que atualmente foi contabilizado que, somente em 2018, os 92 tribunais brasileiros receberam um total de 28 milhões de novos casos, proferiram 31,8 milhões de sentenças e possuem pendentes de julgamento um total de 78,7 milhões de casos, sendo que cerca de 79,7\% estão totalmente em meio eletrônico. ${ }^{27}$

Por meio da Resolução n ${ }^{\circ}$ 345/2020, o CNJ trouxe regras gerais a respeito da adoção do juízo 100\% digital. Tal Resolução estabelece que o Juízo 100\% digital é opcional, tanto em relação aos Tribunais que aderirem ao sistema de atendimento digital, como para os jurisdicionados em se submeterem ao procedimento. Como o próprio nome diz, todos os atos processuais serão praticados exclusivamente por meio eletrônico e remoto, incluindo as audiências e sessões de julgamento, que vão ocorrer exclusivamente por videoconferência.

Assim, a opção de escolher pela tramitação digital se dá na distribuição da peça exordial, contudo é garantida ao jurisdicionado a possibilidade de reconsiderar a decisão pela tramitação digital, cabendo sublinhar que não há sentido em condicionar o exercício dessa prerrogativa apenas a uma janela de oportunidade posterior à apresentação da contestação. Ou seja, antes mesmo de apresentada a contestação, nada impede que também o autor manifeste sua vontade no sentido de reconsiderar a opção originalmente feita, se aplicando a mesma lógica para o demandado que pode reconsiderar a decisão, havendo optado ou não pela tramitação digital. ${ }^{28}$ Salienta-se, contudo, que entre apresentação da

26 COELHO, Fabio Ulhoa. O Judiciário e a tecnologia. Disponível em: https://migalhas.uol.com.br/depeso/298546/o-judiciario-e-a-tecnologia

${ }^{27}$ BRASIL. Conselho Nacional de Justiça. Inteligência artificial na Justiça. Coordenação: José Antônio Dias Toffoli; Bráulio Gabriel Gusmão. - Brasília: CNJ, 2019. p. 10

${ }^{28}$ REICHELT. Luis Alberto. Reflexões sobre o modelo do "juízo 100\% digital” à luz do direito fundamental ao acesso à justiça. In: SARLET, Ingo Wolfgang; RUARO, Regina Linden; LEAL, Augusto Antônio 
contestação e a sentença, as partes somente poderão exercer tal direito de reconsideração em uma única oportunidade.

Doravante, ficará a cargo dos tribunais de justiça que aderirem ao programa de atendimento $100 \%$ digital o fornecimento de infraestrutura de informática e de telecomunicação necessárias ao funcionamento das unidades jurisdicionais incluídas no "Juízo 100\% Digital29", que deverá prestar, no horário de atendimento ao público, atendimento remoto por telefone, e-mail, chamadas de vídeo, aplicativos digitais ou outros canais de comunicação definidos pelo tribunal. Ainda, o atendimento aos advogados pelos magistrados ocorrerá mediante manifestação de interesse pelo procurador da parte, com dia e hora, por meio eletrônico indicado pelo tribunal e a resposta sobre o atendimento deverá ser feita em até 48 horas, salvo em situações de urgência.

Ademais, conforme os termos da Resolução, os tribunais que implementarem a sistemática devem com 30 dias de antecedência comunicar ao Conselho Nacional de Justiça, junto com o detalhamento da implantação. O projeto será avaliado após 1 (um) ano de sua instalação, mediante indicadores de produtividade e celeridade informados. Ao final do período, o tribunal optar pela manutenção, pela descontinuidade ou por sua ampliação, comunicando a deliberação ao CNJ.

Deve-se ressaltar que as disposições da Resolução CNJ no 345/2020 para o emprego da tecnologia na prestação jurisdicional não podem resultar na dispensa de orientação do sistema de justiça de modo a respeitar a livre vontade do jurisdicionado. A jurisdição encontra seu verdadeiro sentido apenas na medida em que considerada à luz do direito fundamental ao acesso à justiça, mostrando-se como expressão de uma das essências do ser humano. Nessa perspectiva, a previsão quanto à possibilidade de escolha da forma dos atos processuais não pode esconder as desigualdades experimentadas por jurisdicionados inseridos em contexto de exclusão digital, nem se transmutar em uma fórmula que, utilizada de maneira cega, acabe por impor restrições desproporcionais ao livre agir daqueles a quem é prometida a oferta de proteção por parte do Poder Judiciário. ${ }^{30}$

Fontanive. (Orgs). Direito, Ambiente e Tecnologia: estudos em homenagem ao professor Carlos Alberto Molinaro. Porto Alegre, RS: Editora Fundação Fênix, 2021. p. 641

${ }^{29}$ Note-se, a título de exemplo, que o Tribunal de Justiça do Rio de Janeiro foi regulamentou o Juízo $100 \%$ Digital pelo Ato Normativo $n^{\circ} 28 / 2020$.

${ }^{30}$ REICHELT. Luis Alberto. Reflexões sobre o modelo do "juízo 100\% digital" à luz do direito fundamental ao acesso à justiça. In: SARLET, Ingo Wolfgang; RUARO, Regina Linden; LEAL, Augusto Antônio 


\section{Processo Digital: Da Competência Territorial para Competência Adequada? Os Núcleos de Justiça 4.0}

É necessário salientar que a resolução a Resolução CNJ no 345/2020 é taxativa ao estabelecer que o juízo 100\% digital em nada altera as regras de competência do Código de Processo Civil. No entanto, em tempos de justiça digital, será realmente necessário que uma demanda necessariamente seja proposta em determinado foro?

Conforme acima mencionado, os critérios para definição do foro competente estão ligados a uma facilitação do acesso à justiça do autor ou do réu, ou da atuação do Poder Judiciário. Se o processo referente a uma ação de conhecimento tramitar integralmente de forma digital, com as audiências sendo realizadas por videoconferência, não nos parece realmente necessário que haja uma vinculação de órgãos jurisdicionais às regras de competência territorial.

Explica-se, havendo a tramitação integral do processo de forma digital, a fase de conhecimento não precisa necessariamente estar ligada a um foro determinado. Isso permitirá rever as regras de competência territorial, buscando-se critérios que possam justificar o uso de um juízo totalmente digital, sobretudo a eficiência na prestação jurisdicional.

Assim, se uma demanda cuidar de matéria que não dependa de prova pericial médica, de engenharia ou de uma inspeção judicial, a tramitação virtual do processo não precisa estar ligada unicamente a um foro, sendo possível se rever a necessidade de vinculação a uma localidade específica. Imagine-se, por exemplo, uma ação de cobrança de dívida, cujas provas sejam documentais e pericial contábil. Tratando-se de juízo online, é indiferente que tal órgão esteja em tal ou qual localidade.

De outro lado, numa ação civil pública ambiental, em que será necessária grande produção de prova pericial e inspeções ao local do dano, parece mais consentânea com o direito de acesso à justiça e com a efetividade a aplicação da regra do artigo $2^{\circ}$ da Lei $n$. $7.347 / 85$, que estabelece a competência do foro do local do dano como funcional para as

Fontanive. (Orgs). Direito, Ambiente e Tecnologia: estudos em homenagem ao professor Carlos Alberto Molinaro. Porto Alegre, RS: Editora Fundação Fênix, 2021. p. 648. 
ações civis públicas. Nesse ponto, cabe recordar as lições de José Carlos Barbosa Moreira, para quem a expressão competência funcional prevista no referido artigo $2^{\circ}$ significa que a competência territorial para as ações civis públicas é de natureza absoluta. ${ }^{31}$

Note-se, outrossim, que nada impede a prática de atos executivos digitais, que cada vez mais são estimulados, e que muitas vezes não estão atrelados ao foro do juízo da execução. É o caso, exemplificativamente, da própria penhora de ativos financeiros, regulamentada no artigo 854 do Código de Processo Civil, pelo qual o juiz determinará para possibilitar a penhora de dinheiro em depósito ou em aplicação financeira, o juiz, a requerimento do exequente, sem dar ciência prévia do ato ao executado, determinará às instituições financeiras, por meio de sistema eletrônico gerido pela autoridade supervisora do sistema financeiro nacional, que torne indisponíveis ativos financeiros existentes em nome do executado, limitando-se a indisponibilidade ao valor indicado na execução.

Note-se que a tramitação digital de processos, seja na fase de conhecimento, mas especialmente na de cumprimento ou nas ações de execução, pode trazer importantes benefícios também para a própria efetividade da atividade jurisdicional, com resultados mais rápidos e melhoras na busca do patrimônio do executado, sendo uma possível via para reduzir as baixas taxas de êxito das execuções no país. ${ }^{32}$

Nessa linha, revendo a aplicação das regras de competência territorial nas execuções, recentemente entendeu o Superior Tribunal de Justiça, ao julgar o Conflito de Competência $n^{\circ}$ 147.746-SP, pela desnecessidade de expedição de carta precatória para a alienação judicial eletrônica de bem situado em outra comarca.

Se o ato de expropriação é eletrônico, torna-se prescindível a remessa de uma carta para outra comarca, podendo o próprio juízo da execução pratica-lo. Ademais, o leilão

\footnotetext{
${ }^{31}$ MOREIRA, José Carlos Barbosa. A expressão competência funcional no art. $2^{\circ}$ da lei da ação civil pública. In: Revista Forense, v. 101, n. 380, p. 179-187, jul./ago., 2005.

${ }^{32}$ De acordo com dados do Relatório “Justiça em Números 2019”, editado pelo Conselho Nacional de Justiça, os processos de execução fiscal representam, aproximadamente, $39 \%$ do total de casos pendentes e $73 \%$ das execuções pendentes no Poder Judiciário, com taxa de congestionamento de $90 \%$. Ou seja, de cada cem processos de execução fiscal que tramitaram no ano de 2018, apenas 10 foram baixados. (CONSELHO NACIONAL DE JUSTIÇA. Relatório Justiça em Número 2019. Disponível em: <https://www.cnj.jus.br/wpcontent/uploads/conteudo/arquivo/2019/08/justica_em_numeros20190919.pdf >. Acesso em 05 de maio de 2020).
} 
eletrônico ainda permite uma maior participação de interessados, ampliando as chances de uma proposta satisfatória pelo bem objeto da execução. ${ }^{33}$

A tecnologia permite, pois, a revisão da ideia de competência territorial e da própria necessidade de cartas precatórias em muitas hipóteses. Salvo em situações de competência absoluta exigida por lei, ou nos casos que demandem provas locais, o processamento das ações nos juízos digitais não exigiria uma aderência da demanda a uma comarca específica.

Isso pode contribuir para uma melhoria da eficiência, da celeridade e da qualidade da prestação jurisdicional, com a especialização dos órgãos digitais. A tecnologia veio para ficar, e é preciso extrair dela as melhores potencialidades em prol da ampliação do acesso à justiça.

Nesse sentido, fundamental mencionar os Núcleos de Justiça 4.0, que tiveram sua instituição autorizada pelo Conselho Nacional de Justiça em abril de $2021 .{ }^{34}$ Trata-se, com efeito, da possibilidade de que os Tribunais instituam núcleos especializados pelos quais os processos que lhe forem encaminhados tramitarão de maneira totalmente digital.

Qualquer processo de competência territorial de um Tribunal poderá ser encaminhado aos Núcleos de Justiça 4.0, desde que haja concordância de ambas as partes envolvidas no conflito. Por exemplo, ação indenizatória de competência territorial da Comarca de Volta Redonda - município situado na região sul do Estado do Rio de Janeiro - poderá ser encaminhada ao Núcleo de Justiça 4.0 eventualmente instituído pelo Tribunal de Justiça fluminense.

Trata-se de mudança forte na análise das regras de competência territorial, a ensejar a sua releitura. Isso porque a instituição dos Núcleos de Justiça 4.0 põe em xeque a ideia de fixação da competência a partir da aderência ao território - a título de exemplo, determinar a competência para a execução por título extrajudicial a partir do local onde a obrigação deva ser satisfeita.

A rigor, os referidos núcleos não necessariamente serão localizados na comarca competente para o processo e julgamento a partir das regras abstratamente previstas no Código de Processo Civil. Considerando a desnecessidade de comparecimento das partes à

\footnotetext{
${ }^{33}$ STJ, CC 147.746/SP, Rel. Ministro NAPOLEÃO NUNES MAIA FILHO, PRIMEIRA SEÇÃO, julgado em 27/05/2020, DJe 04/06/2020.

${ }^{34}$ CONSELHO NACIONAL DE JUSTIÇA. Núcleos de Justiça 4.0 vão aprimorar acesso ao Judiciário. Disponível em https://www.cnj.jus.br/nucleos-de-justica-4-0-vao-aprimorar-acesso-ao-judiciario/. Acesso em 19.04.2021.
} 
prática de atos processuais, bem como de modo a racionalizar os custos na sua implementação e manutenção, a tendência natural é que os Núcleos de Justiça 4.0 sejam localizados na maior comarca ou seção judiciária daquele Tribunal.

Neste cenário, falar em competência territorial a partir das mesmas bases antes estabelecidas, tendo como premissa um Poder Judiciário fortemente estabelecido a partir de processos físicos e/ou da prática presencial de atos processuais, certamente não será a medida mais adequada. A justiça digital exige mudanças nesta análise, diante das novas possibilidades abertas em razão da utilização de meios tecnológicos na atividade jurisdicional.

\section{Considerações Finais}

Em síntese conclusiva, percebe-se que a tramitação digital de demandas que se adequem dentro das características do processo $100 \%$ digital, tais como as que o mérito seja demonstrado mediante análise de prova documental, se mostra uma interessante medida para contribuir com o melhor funcionamento do Poder Judiciário. A tramitação 100\% digital torna a tutela jurisdicional mais rápida e eficiente, tanto do ponto de vista do Judiciário e das funções essenciais à justiça, como dos jurisdicionados.

Ademais, pode se mostrar benéfico o ajuizamento digital de demandas em que sejam necessários conhecimentos técnicos especializados sobre o objeto da causa, o que faz com que a prestação jurisdicional ganhe sob o ponto de vista qualitativo, considerando que, com exceção das capitais, na maioria dos casos não existem tantas varas especializadas nas comarcas, principalmente nas do interior.

Portanto, a ampliação da distribuição eletrônica de demandas que se mostrem hábeis à resolução virtual permite a revisão da regra de competência territorial, o que pode ampliar a própria proteção à garantia fundamental de acesso à justiça.

\section{REFERÊNCIAS}

ASSIS, Araken de. Processo civil brasileiro, volume I [livro eletrônico]: parte geral: fundamentos e distribuição de conflitos / Araken de Asssis. -2 ed. -São Paulo. Editora Revista dos Tribunais, 2016. 
BRASIL, Conselho Nacional de Justiça. Relatório Justiça em números 2016. Brasília: CNJ, 2016.

BRASIL, Conselho Nacional de Justiça. Relatório Justiça em números 2018. Brasília: CNJ, 2018.

BRASIL, Conselho Nacional de Justiça. Relatório Justiça em números 2019. Brasília: CNJ, 2019.

BRASIL, Conselho Nacional de Justiça. Inteligência artificial na Justiça. Coordenação: José Antônio Dias Toffoli; Bráulio Gabriel Gusmão. - Brasília: CNJ, 2019.

CABRAL, Antonio do Passo. Processo e Tecnologia: novas tendências. In: WOLKART, Erik Navarro (coord.) et al. Direito, Processo e Tecnologia. 1. ed. São Paulo: Thomson Reuters Brasil, 2020.

CAPPELLETTI, Mauro e GARTH, Bryant. Acesso à justiça. Porto Alegre: Sergio Antonio Fabris Editor, 1988.

COELHO, Fabio Ulhoa. O Judiciário e a tecnologia. Disponível em: https://migalhas.uol.com.br/depeso/298546/o-judiciario-e-a-tecnologia

DIDIER JUNIOR, Fredie. Curso de Direito Processual Civil. Vol. I. 19. ed. Salvador: JusPODVM, 2017.

DINAMARCO. Cândido Rangel. A instrumentalidade do processo. 12. ed. São Paulo: Malheiros, 2005.

ECKSCHMIDT, Thomas; MUHR, Diana; MAGALHÃES, Mario E. S. Do Conflito ao Acordo na Era Digital (Meios Eletrônicos para Solução de Conflitos). 2. ed. São Paulo: Moderattus, 2016.

KOHL, Uta. Jurisdiction and the internet: Regulatory competence over Online Activity. New York: Cambridge University Press, 2010.

LEINER BARRY M. et al A Brief History of Internet. ACM SIGCOMM Computer Communication Review, v. 39, n 5, Oct. 2009.

MOREIRA, José Carlos Barbosa. A expressão competência funcional no art. $2^{\circ}$ da lei da ação civil pública. In: Revista Forense, v. 101, n. 380, p. 179-187, jul./ago., 2005.

NERY JÚNIOR, Nelson; NERY, Rosa Maria de Andrade. Código de Processo Civil Comentado. 18 ed. São Paulo: Revista dos Tribunais, 2018. 
REICHELT. Luis Alberto. Reflexões sobre o modelo do "juízo 100\% digital" à luz do direito fundamental ao acesso à justiça. In: SARLET, Ingo Wolfgang; RUARO, Regina Linden; LEAL, Augusto Antônio Fontanive. (Orgs). Direito, Ambiente e Tecnologia: estudos em homenagem ao professor Carlos Alberto Molinaro. Porto Alegre, RS: Editora Fundação Fênix, 2021.

RODRIGUES, Marco Antonio dos Santos. A modificação do pedido e a causa de pedir no processo civil. Rio de Janeiro: GZ, 2014

RODRIGUES, Marco Antonio. Acesso à justiça, resolução on-line de conflitos e interesse de agir. In: Revista de Processo, vol. 314, p. 39-53, abril/2021.

RODRIGUES, Marco Antonio. Processos judiciais e coronavírus. Disponível em: $<$ https://www.jota.info/opiniao-e-analise/artigos/processos-judiciais-e-coronavirus28032020>.

SUSSKIND, Richard. Online courts and the future of justice. Oxford University Press. UK, 2019.

SUSSKIND, Richard. Tomorrow Lawyers: An Introduction to your Future. 2. ed. London: Oxford University, 2017.

THEODORO JUNIOR, Humberto. Curso de Direito Processual Civil. Vol. I. 59 ed. Rio de Janeiro: Forense, 2018.

VASCONCELOS, Ronaldo; CARNAÚBA, César Augusto Martins. Custo de Transação do Processo e Online Dispute Resolution: um sistema multiportas 4.0 economicamente eficiente. In: WOLKART, Erik Navarro (coord.) et al. Direito, Processo e Tecnologia. 1. ed. São Paulo: Thomson Reuters Brasil, 2020.

YARSHELL, Flávio Luiz; GOMES, Adriano Camargo. Internet e limites da jurisdição: Uma breve análise à luz do direito processual civil. In: WOLKART, Erik Navarro (coord.) et al. Direito, Processo e Tecnologia. 1. ed. São Paulo: Thomson Reuters Brasil, 2020 . 